Disponível em

http://www.anpad.org.br/rac

RAC, Rio de Janeiro, v. 17, n. 5, art. 6, pp. 620-641, Set./Out. 2013

(oc) EY-No

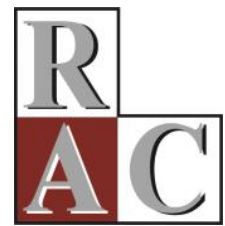

\title{
A Ética dos Alunos de Administração e de Economia no Ensino Superior
}

\section{Management and Economics Student Ethics in Higher Education}

\author{
Paulo Gama
}

E-mail: gama@fe.uc.pt Faculdade de Economia - Universidade de Coimbra Avenida Dias da Silva, 165, 3004-512, Coimbra, Portugal.

Paulo Peixoto

E-mail: pp@fe.uc.pt

Centro de Estudos Sociais - Faculdade de Economia - Universidade de Coimbra Avenida Dias da Silva, 165, 3004-512, Coimbra, Portugal.

Ana Maria Seixas E-mail: anaseixas@fpce.uc.pt Faculdade de Psicologia e das Ciências da Educação - Universidade de Coimbra Rua do Colégio Novo, Apartado 6153, 3001-802, Coimbra, Portugal.

Filipe Almeida E-mail: falmeida@fe.uc.pt Centro de Estudos Sociais - Faculdade de Economia - Universidade de Coimbra Avenida Dias da Silva, 165, 3004-512, Coimbra, Portugal.

Denise Esteves

E-mail: deniseesteves@gmail.com

Centro de Estudos Sociais - Universidade de Coimbra Colégio de S. Jerónimo, Apartado 3087, 3000-995, Coimbra, Portugal. 


\title{
Resumo
}

A fraude acadêmica cometida por alunos universitários é um problema de ordem institucional e social, com efeitos nocivos na eficiência do mercado de trabalho e comprometedores da confiança da sociedade nas organizações, especialmente grave no caso de futuros decisores gerenciais. O objetivo deste artigo é estudar a atitude dos alunos de administração e economia perante a fraude acadêmica, a sua percepção sobre a frequência desta, a gravidade que atribuem aos diferentes tipos de fraude, o que a motiva e o que a poderá inibir. É também apresentada uma nova tipologia de fraude acadêmica e são propostos dois novos indicadores que avaliam a predisposição para a fraude (IPF) e a predisposição para a denúncia (IPD). Empiricamente, foram inquiridos 1.276 alunos de instituições de ensino superior portuguesas, utilizando um questionário projetivo. Os resultados revelam a prevalência da fraude associada à avaliação por exame escrito e a significativa ausência de denúncia de fraude, destacando a transação de trabalhos acadêmicos como a prática mais condenável. O IPF é maior entre os piores alunos, e entre os que não se reconhecem no curso ou na instituição. O estudo revela, ainda, que o principal motivo para transgredir está relacionado com o sucesso acadêmico, e que o principal fator inibidor, com a dissuasão.

Palavras-chave: fraude acadêmica; ética; ensino superior.

\begin{abstract}
Academic fraud committed by higher education students is a problem with institutional and social ramifications, with undesired effects on labor market efficiency and compromising societal trust in organizations, and is especially serious for future managers. This paper studies the attitudes business and economics students have towards academic fraud, their perceptions of the frequency and gravity of the various types of fraud by committed by fellow students, and their opinions on factors that motivate or inhibit it. The paper proposes a new four-dimensional framework for analyzing fraud and proposes two new indicators to evaluate predisposition to commit fraud (PCF) and to evaluate predisposition to denounce fraud (PDF). Empirically, 1,276 students from Portuguese universities were surveyed using a new projective questionnaire, which was answered in person in the classroom. Results show that the highest incidence of fraud is associated with written exam assessment and that denunciation is almost non-existent. Buying and selling academic work is seen as the most condemnable fraudulent behavior. Higher PCF is found among the worst students and those less committed to their course or university. The primary reason for ethical misconduct is related to academic achievement and the main factor preventing it is dissuasion.
\end{abstract}

Key words: academic fraud; ethics; higher education. 


\section{Introdução}

As grandes transformações tecnológicas e políticas que ocorreram no mundo durante as últimas décadas tornaram mais fácil o acesso à informação e reforçaram a capacidade reivindicativa das sociedades contra os múltiplos abusos corporativos e institucionais que violam ou comprometem os seus direitos. No contexto empresarial, diversos escândalos com significativo impacto mediático atraíram a atenção pública para o comportamento ético das empresas (Almeida, 2007; McCabe, Butterfield, \& Treviño, 2006; Murcia \& Borba, 2005; Witherspoon, Maldonado, \& Lacey, 2012), alimentando o debate sobre a fraude e a transgressão cometidas por empresários e gestores. Os estudos e os ensaios acadêmicos sobre a ética empresarial, suas causas e seus efeitos, têm-se multiplicado. No entanto, a pesquisa sobre a ética dos alunos de administração e de economia no meio universitário, como antecedente da sua ética profissional, tem sido mais rara, especialmente em contextos fora dos EUA.

A fraude acadêmica cometida pelos alunos no ensino superior, quando não detetada, é um fator que perturba a justiça comparativa da avaliação no contexto universitário, mas que prolonga seus efeitos na sociedade por meio de profissionais impreparados e predispostos à transgressão legal e ética. A fraude dos alunos e a injustiça na sua avaliação é um problema com implicações em vários níveis da vida coletiva, afetando não só a reputação das instituições universitárias (Walker, 2010), mas podendo também ser decisivo para o desenvolvimento econômico e político de um país (Teixeira \& Rocha, 2010). O intenso debate atual sobre questões de natureza ética no domínio profissional alerta para a importância fundamental de conhecer melhor o fenômeno da fraude no ensino superior, enquanto preditor de comportamentos futuros (Rumyantseva, 2005).

A pesquisa sobre este tema é, no entanto, repleta de dificuldades. Por um lado, ainda não existe uma definição simples de fraude acadêmica que delimite o conceito e determine as suas fronteiras teóricas (Teixeira \& Rocha, 2010). Por outro, decorrente dessa indefinição, a ausência de uma medida clara que inclua as diversas dimensões da fraude constitui outro obstáculo à comparabilidade dos estudos sobre a ética dos alunos do ensino superior (Walker, 2010). Em geral, a medida mais utilizada para estudar a fraude acadêmica é copiar numa prova escrita, habitualmente sem sequer analisar se a fraude é concretizada com recurso a materiais não autorizados, a tecnologias de comunicação ou à cópia por um colega. Outros indicadores comuns, amplificados pelo uso de novas tecnologias, incluem copiar de fontes não citadas, pegar trabalhos realizados por outra pessoa, solicitar ajuda de colegas durante as provas ou falsificar bibliografia (Teixeira \& Rocha, 2010; Witherspoon et al., 2012). Outra das limitações habituais desse tipo de estudos é o seu limitado potencial de generalização, já que raramente incluem amostras aleatórias ou estratificadas. Mas talvez a maior das limitações seja a fiabilidade das respostas, já que se trata de um assunto com implicações morais, socialmente sensível, e cujo questionamento, embora anênimo, refere-se habitualmente à conduta do próprio inquirido (Walker, 2010). No entanto, apesar das suas reconhecidas insuficiências e limitações, esse campo de estudo tem-se expandido nos últimos anos, contando já com um corpo robusto de resultados empíricos que permite inferências relativamente seguras sobre a realidade. De fato, estudos recentes sugerem que a fraude acadêmica entre os alunos tem aumentado em todo o mundo (McCabe, Treviño, \& Butterfield, 2001), com especial incidência no Leste e no Sul da Europa (Teixeira \& Rocha, 2010).

No caso particular dos alunos de administração, a sua percepção sobre a aceitabilidade de determinadas práticas acadêmicas durante a realização dos cursos parece ser um indicador razoável do critério moral que adotarão no futuro em ambiente profissional, para julgar o comportamento empresarial (Lawson, 2004; Nonis \& Swift, 2001; Smyth, Davis, \& Kroncke, 2009). Embora alguns estudos sugiram que esses alunos revelem uma propensão para cometer fraude maior do que os gestores no exercício efetivo da função gerencial (Wood, Longenecker, McKinney, \& Moore, 1988), parece consolidar-se a evidência empírica de que a fraude acadêmica cometida por alunos dos cursos de administração tem aumentado significativamente (McCabe et al., 2006), mesmo em comparação com alunos de outros cursos (McCabe, 2009). 
Os estudos sobre a fraude acadêmica têm incidido predominantemente sobre a realidade norteamericana, sendo ainda escassos na Europa (Teixeira \& Rocha, 2010). São ainda mais raros os estudos sobre a fraude acadêmica em Portugal, sendo quase inexistentes aqueles que se dedicam, neste contexto, exclusivamente à análise da ética dos alunos de administração e de economia. Por outro lado, é ainda muito pouco comum questionar-se a opinião dos alunos sobre os fatores que motivam a fraude e aqueles que a poderão inibir (Malgwi \& Rakovksi, 2009). Este artigo ${ }^{(1)}$ visa contribuir para colmatar essas lacunas, apresentando os resultados de um estudo sobre a atitude perante a fraude acadêmica de alunos de administração e de economia de instituições de ensino superior portuguesas. Ao mesmo tempo, procurou-se igualmente superar algumas das limitações identificadas neste tipo de pesquisa, propondo uma delimitação conceitual para a fraude acadêmica, aplicando um novo questionário presencial alinhado com a tipologia de fraudes sugerida por essa definição e recorrendo a uma amostra multirregional e multi-institucional tendencialmente representativa do ensino superior em Portugal.

\section{A Fraude Acadêmica: Métodos e Determinantes}

A violação de normas acadêmicas que regulam a conduta dos alunos em ambiente universitário tornou-se, nas últimas décadas, um problema ao qual instituições, governantes, acadêmicos e comunicação social têm dedicado atenção crescente. As práticas acadêmicas fraudulentas comprometem a justiça dos resultados da avaliação dos alunos, o que origina um desajustamento entre as competências reais e as habilitações formais, gerando múltiplas ineficiências no mercado de trabalho e alimentando um sentimento de frustração junto de quem respeita as normas e que se vê ser ultrapassado por quem as viola. Ambos os efeitos são nocivos para o desenvolvimento econômico e o progresso social de um país.

Os tipos de fraude mais estudados e relatados como mais frequentes são a cópia numa prova escrita e o plágio (Witherspoon et al., 2012). A esse respeito, Brandt (2002) identificou quatro formas de plágio: apropriar-se do trabalho alheio sem consentimento nem reconhecimento do autor; submeter um trabalho realizado por outra pessoa e assumir autoria; copiar parcialmente por fontes não identificadas no trabalho; referir fontes sem apresentar referência bibliográfica. Apesar desse não ser um problema recente (Sutherland-Smith, 2010), as novas tecnologias de informação e de comunicação vieram tornar mais fácil o plágio, a cópia e a proliferação de métodos alternativos de fraude (Bazerman, 2010; Gomes, 2011; Mayhew, Seifert, \& Pascarella, 2010; Scanlon, 2003). Witherspoon, Maldonado e Lacey (2012) estudaram os métodos de fraude utilizados, comparando os tradicionais com os modernos que recorrem a novas tecnologias. Os autores identificaram como métodos tradicionais a utilização de materiais não autorizados no exame, copiar por um colega ou fornecer respostas a um colega, mentir ao professor para ter mais tempo para entregar o trabalho, falsificar resultados, fazer um exame por um colega, falsificar assinatura de colega em uma aula, copiar trabalho de um colega ou pedir que um colega o faça por si, comprar trabalho, não denunciar a fraude. Os métodos modernos incluem a compra de trabalhos online de empresas especializadas, a cópia de trabalhos pela Internet, a utilização de PDA, calculadoras científicas e celulares para fazer cópias durante as provas ou comunicar-se com outros colegas que o auxiliem na resolução do exame. Os resultados do estudo revelaram que 79,7\% dos alunos havia cometido algum tipo de fraude pelo menos uma vez no último ano, e que os alunos que cometem mais fraudes preferem os métodos modernos. No entanto, apesar do recurso crescente a métodos modernos, estes complementam os tradicionais, não os substituem. Segundo os autores, os alunos que cometem fraude fazem-no recorrendo ao que têm disponível, independentemente de ser um método tradicional ou moderno (Witherspoon et al., 2012).

A análise deste fenômeno não pode, no entanto, ser desligada do estudo dos fatores individuais, institucionais e culturais que o influenciam e determinam. Numa recente pesquisa transnacional envolvendo 7213 alunos de economia e administração de 42 universidades em 21 países, Teixeira e Rocha (2010) estudaram os determinantes da prática fraudulenta de copiar numa prova escrita. As 
autoras relatam que 61,7\% dos alunos admitem copiar (com mais propensão na Europa de Leste, Brasil, França e Espanha) e que $90 \%$ dos alunos já observou colegas copiando, o que sugere que o problema talvez seja mais grave do que evidenciado quando relatado na primeira pessoa especialmente na América Latina e Sul da Europa. Os resultados revelam que a propensão para praticar esse tipo de fraude é influenciada pelos benefícios percepcionados, pela percepção sobre frequência com que outros a praticam, pela proximidade com quem copia, pela proximidade do fim do curso, pela percepção sobre a ligeireza das sanções, pela existência de código de honra na instituição, e pela região/país de origem (Teixeira \& Rocha, 2010).

Efetivamente, o contexto cultural parece determinante na formação da atitude dos alunos perante a fraude, confirmando-se também aqui os resultados de estudos anteriores que registram menor incidência desse fenômeno nos países do norte da Europa e da América, contrastando com a alta prevalência da fraude no Sul e no Leste europeu, e na América Latina, especialmente no Brasil (Crittenden, Hanna, \& Peterson, 2009; Teixeira \& Rocha, 2010). Uma explicação pode estar relacionada com a permissividade do ambiente acadêmico e os sinais institucionais, que ignoram ou desincentivam a fraude. A existência de códigos de honra tem sido recorrentemente referida como um inibidor da fraude acadêmica (McCabe, Treviño, \& Butterfield, 2002), uma vez que as instituições com esses códigos revelam uma atitude mais favorável e assertiva em relação às políticas de prevenção e de sanção da fraude (McCabe, Butterfield, \& Treviño, 2003). Esses resultados parecem ser corroborados pelo estudo de Teixeira e Rocha (2010), no qual se confirma que a fraude tende a ter maior incidência entre os alunos que esperam sanções mais leves se forem pegos em flagrante, sendo essa expectativa culturalmente robusta (nos países escandinavos, os alunos esperam sanções mais duras do que os alunos do Sul da Europa ou da América Latina).

Outro determinante da fraude acadêmica pode ser a pressão atual exercida sobre os alunos para que alcancem boas notas e, com isso, empregos promissores e uma posição estável no mercado de trabalho (Callahan, 2004; Wilkerson, 2009). Essa pressão competitiva pode desequilibrar a relação de forças entre a tentação da fraude e a reprovação moral do ato sentidas pelo aluno. Nesse contexto, Silva, Rocha, Otta, Pereira e Bussad (2006) testaram a variável competitividade em duas universidades públicas do Estado de São Paulo, concluindo que a prática da cola é mais frequente nas universidades em que não há competição do que nas universidades em que há competição. Alguns estudos sugerem, no entanto, que existe uma correlação negativa entre a prática fraudulenta e a média global do aluno no curso (Bunn, Caudill, \& Gropper, 1992), o que pode ser explicado pelo fato do aluno com melhor média ter mais a perder do que ao aluno com piores notas (Hrabak et al., 2004). Esse argumento parece não ser suportado pelos resultados de Teixeira e Rocha (2010), segundo os quais, nos países onde os alunos revelam menor propensão para a fraude - com sanções mais pesadas e, portanto, com maior risco - é maior a proporção de bons alunos que admitem ter cometido fraude comparativamente com a proporção de maus alunos que admitem tê-lo feito. As autoras argumentam que a percepção sobre o benefício imediato num dado exame é mais relevante como explicador da fraude do que a média geral do aluno no curso (Teixeira \& Rocha, 2010).

É também comum buscar explicação para a predisposição transgressora no gênero, sendo habitual que a diferença de atitude, quando encontrada, identifique o homem como mais propenso a cometer fraude do que a mulher (Mirshekary \& Lawrence, 2009; Rakovski \& Levy, 2007). Vários autores reconhecem, no entanto, que essa diferença tem vindo a esbater-se, sendo cada vez mais comum homens e mulheres revelarem comportamentos indiferenciados (Teixeira \& Rocha, 2010; Walker, 2010). Nesses casos, a convergência de expectativas em relação a ambos os gêneros e a aproximação dos papéis sociais respectivos pode explicar esta aparente indiferença.

A idade do aluno, relacionada com o ano do curso que frequenta, é também frequentemente estudada. Os resultados são inconclusivos, embora alguns estudos sugiram que a propensão para cometer fraude aumente à medida que se evolui no curso (Marsden, Carroll, \& Neill, 2005; Walker, 2010). Pode especular-se que os alunos mais experientes tendem a plagiar mais devido à pressão competitiva, à constatação da impunidade ou por acomodação a uma cultura acadêmica que ainda não está acessível aos alunos do primeiro ano. 
Num estudo sobre o plágio cometido por alunos universitários, Walker (2010) analisou as práticas reais de 569 alunos de uma universidade da Nova Zelândia ao longo de cinco anos, concluindo que os alertas e as ameaças não são suficientes para reduzir significativamente o plágio. Apesar dos alunos terem sido informados prévia e enfaticamente sobre o plágio, as suas implicações, as sanções envolvidas e que os trabalhos seriam avaliados por um software antiplágio, em média $26,2 \%$ dos alunos cometeram algum tipo de transgressão. Curiosamente, os resultados sugerem que a proximidade e o ensino presencial parecem não diminuir a fraude, antes pelo contrário, verificando-se maior incidência nos alunos do ensino presencial do que naqueles de ensino à distância. Segundo o autor, o aluno-tipo, que mais comete fraude, tem o seguinte perfil: é estrangeiro, tem mais de 30 anos e frequenta o ensino presencial no $4^{\circ}$ ano do curso (Walker, 2010).

Independentemente dos contextos particulares de cada pesquisa, a fraude acadêmica parece ser um fenômeno em significativa ascensão nos meios universitários em todo o mundo, estando associada a características pessoais dos alunos, e sendo influenciada pela cultura de tolerância ou exigência dos professores e pela efetividade das políticas institucionais de combate e desincentivo à fraude. Nos cursos de economia e de administração, em que é formada uma parte significativa dos dirigentes e decisores institucionais do futuro, o caso torna-se especialmente grave devido às implicações coletivas de um sistema educacional injusto e ineficaz. Segundo Teixeira e Rocha (2010), 60\% dos 7213 alunos de economia e administração questionados pelas autoras não reconhece que copiar nos exames seja um problema sério na academia, mesmo em países onde a percentagem de cópia é elevada. Esse resultado inquietante parece sugerir uma aceitação da fraude como prática amoral, tornando urgente aprofundar a busca de entendimento para a forma como os alunos se posicionam perante os diferentes tipos de fraude, e quais os fatores que consideram que a motiva, bem como aqueles que têm o potencial de inibi-la.

\section{Objetivo do Estudo}

Os cargos executivos e de alta administração de empresas tornaram-se alvo de redobradas atenções devido ao impacto profundamente negativo que o comportamento imoral, nessas funções, pode significar para a economia e para a sociedade em geral. A formação universitária, entendida em sentido lato, pode desempenhar um papel decisivo na consolidação de um sistema de valores morais alinhado com um padrão ético exigente, mas também pode estimular condutas vulneráveis à transgressão e à ação imoral. O estudo da ética dos alunos do ensino superior é, por isso, essencial para compreender o papel da educação formal na estruturação de uma ética pessoal, enquanto fator que antecede e influencia a conduta moral no contexto profissional futuro. Assim, o objetivo desta pesquisa exploratória é analisar a atitude dos alunos de cursos de economia e de administração do ensino superior perante a fraude acadêmica cometida por seus pares. Em concreto, pretende-se conhecer qual a sua percepção sobre a frequência das práticas fraudulentas entre colegas, qual a gravidade que atribuem aos diferentes tipos de transgressão e quais os fatores que, na sua opinião, os determinam ou poderão inibir.

\section{Tipologia da Fraude Acadêmica e Perguntas de Pesquisa}

Uma das lacunas identificadas nos estudos sobre fraude acadêmica refere-se à ausência de um conceito agregador que permita delimitar com clareza as fronteiras da transgressão (Teixeira \& Rocha, 2010). Como contribuição teórica para o desenvolvimento do campo, propõe-se, nesta pesquisa, uma tipologia da fraude acadêmica baseada no seguinte conceito: constituirá fraude acadêmica todo ato ou omissão consciente que possa comprometer a justiça na avaliação comparativa dos desempenhos, competências e conhecimentos dos alunos entre si. 
Nestes termos, a fraude acadêmica pode ser cometida pelos alunos, pelos docentes, por funcionários das instituições de ensino, por agentes externos ou pela própria instituição no âmbito da sua política pedagógica. Apesar da relevância dos vários níveis de análise, esta pesquisa centra-se apenas no estudo da fraude acadêmica cometida pelos alunos, entendida como qualquer transgressão moral praticável por um discente no contexto das suas relações acadêmicas e das suas responsabilidades perante professores, colegas e a instituição que o acolhe. Assim, com base nesse enquadramento, propõe-se a seguinte tipologia da fraude acadêmica:

\section{Apropriação de trabalho alheio}

. apropriação de trabalho alheio com colaboração ativa de outrem;

. apropriação de trabalho alheio sem intervenção ativa de outrem.

\section{Simulação de trabalho não realizado}

. plagiar-se a si mesmo;

. falsificar dados e resultados.

\section{Facilitação da fraude a terceiros}

- facilitar a fraude com benefício próprio;

. facilitar a fraude com risco de prejuízo próprio;

. facilitar a fraude com efeito neutro para si próprio.

\section{Ocultação da fraude (não denúncia da fraude cometida por terceiros)}

Tal como apresentada, esta tipologia prevê 4 tipos de ordem superior de fraude acadêmica e 14 tipos de ordem inferior (considerando que o tipo "Ocultação da fraude" se desdobra nos mesmos 7 subtipos dos restantes tipos de ordem superior). Tratando-se de um estudo exploratório, pretende-se analisar os resultados gerais em busca de um entendimento tão detalhado quanto possível sobre a forma como pensam os alunos de administração e de economia sobre a fraude acadêmica. Eis as cinco perguntas às quais se pretende responder nesta pesquisa:

1. Quais as práticas de fraude acadêmica mais comuns?

2. Quais as práticas de fraude acadêmica que os alunos consideram mais graves e menos graves?

3. Qual a relação entre as diferentes práticas de fraude acadêmica do ponto de vista da gravidade que os alunos atribuem a cada uma? Qual a tipologia subjacente aos diferentes níveis de gravidade?

4. Quais os motivos principais para cometer fraude acadêmica?

5. Quais os principais fatores que poderão inibir a fraude acadêmica?

\section{Método de Pesquisa}

\section{Amostra e coleta de dados}

Uma vez que o objetivo desta pesquisa é estudar a ética de alunos do ensino superior em Portugal, foi selecionada uma amostra de alunos de cursos de economia e de administração de instituições de ensino superior portuguesas, tendo como referência o universo constituído pela totalidade dos alunos inscritos no ensino superior em Portugal no ano letivo 2009/2010. A partir deste 
universo, efetuou-se a seleção das instituições e do número de alunos a inquirir por curso com base num critério de cálculo que mantém a proporção representativa de cada área de educação e formação e de cada subsistema de ensino (universitário e politécnico, e, em ambos, público e privado). Assim, com base nesses princípios, a amostra representativa da área de economia e administração no ensino superior em Portugal inclui 350 alunos de economia distribuídos por 7 cursos em 7 instituições e 2012 alunos de administração e áreas afins distribuídos por 34 cursos em 27 instituições.

A coleta de dados foi realizada com base na aplicação, em sala de aula, de um questionário de resposta fechada, com a presença de um elemento da equipe de pesquisa disponível para esclarecer qualquer dúvida. Apenas foram retidos na amostra alunos de nacionalidade portuguesa e com pelo menos dois anos de inscrição no ensino superior. Dadas essas restrições e as exigências do método de seleção da amostra, foram coletadas 1276 respostas válidas, representando uma taxa de resposta de $54 \%$ em relação à amostra desejada.

\section{O questionário}

O questionário utilizado nesta pesquisa constitui uma proposta original para coleta de dados e para o estudo da fraude acadêmica cometida por alunos no ensino superior. A sua versão inicial foi inspirada em diversos instrumentos de pesquisa disponíveis na literatura, em especial as propostas de Morris e Kilian (2006), com adaptações sugeridas pelos trabalhos de McCabe (1999) e de Rennie e Rudland (2003). Foram posteriormente realizados debates com alunos sobre os diversos aspectos da fraude acadêmica, com vista a enriquecer os conteúdos e adequar a linguagem. Foi realizado um testepiloto com 452 alunos de quatro graduações (Almeida, Gama, \& Peixoto, 2010), após o qual foram corrigidas algumas questões e acrescentadas novas propostas. Uma nova versão foi apresentada a alguns docentes para se pronunciarem e, com base em todas as contribuições, foi aplicado, em fase de pré-teste, a 372 alunos de oito cursos de graduação. Finalmente, após estas diversas fases de validação, alcançou-se a versão final do questionário, que é decomposto nas seguintes partes principais: PARTE 1 - caracterização sociodemográfica e situação acadêmica dos alunos; PARTE 2 - questionamento projetivo sobre nove cenários de fraude acadêmica (abrangendo os 4 tipos de fraude decompostos em 9 práticas ativas e 9 situações de ocultação - não denúncia); PARTE 3 - questionamento sobre a frequência da fraude, os motivos que a determinam e as ações que a podem inibir.

Na PARTE 2 do questionário, é solicitado aos alunos que se pronunciem sobre a gravidade de 7 práticas de apropriação e 2 de simulação correspondentes a nove cenários simulados, tal como apresentado na Tabela 1. Em cada cenário, é também perguntado aos alunos se eles fariam o mesmo caso estivessem em igual situação, e se a denunciariam caso tivessem conhecimento dela.

Tabela 1

Tipos e Práticas de Fraude Acadêmica

\begin{tabular}{lll}
\hline \multicolumn{2}{l}{ Tipos de Fraude } & Práticas de Fraude \\
\hline APROPRIAR & Apropriação COM colaboração & Comprar trabalho. \\
& & Aceitar ajuda de familiar. \\
& Copiar em exame. \\
& Assinar trabalho. \\
& Apropriação SEM colaboração & Copiar trabalhos. \\
& & Copiar escondido. \\
& Copiar da Internet. \\
\hline SIMULAR & Autoplágio & Apresentar o mesmo trabalho. \\
& Falsificar dados e resultados. & Inventar dados. \\
\hline
\end{tabular}




\section{Tabela 1 (continuação)}

\begin{tabular}{lll}
\hline Tipos de Fraude & Práticas de Fraude \\
\hline FACILITAR & $\begin{array}{l}\text { Facilitar a fraude com benefício } \\
\text { próprio. }\end{array}$ & Vender trabalho. \\
& $\begin{array}{l}\text { Facilitar a fraude com risco de prejuízo } \\
\text { próprio. }\end{array}$ & Deixar copiar. \\
& $\begin{array}{l}\text { Facilitar a fraude com efeito neutro } \\
\text { para si próprio. }\end{array}$ & Permitir autoria. \\
\hline OCULTAR & $\begin{array}{l}\text { Ocultar a fraude (não denúncia da } \\
\text { fraude cometida por terceiros). }\end{array}$ & Não denunciar compra. \\
& Não denunciar colaboração. \\
& Não denunciar cópia camuflada em exame. \\
& Não denunciar falsificação de dados. \\
& Não denunciar apresentação do mesmo trabalho. \\
& Não denunciar cópia por outro colega em exame. \\
& Não denunciar participação em grupo sem autoria. \\
& Não denunciar plágio por trabalho de colega. \\
& Não denunciar cópia pela Internet. \\
\hline
\end{tabular}

Este questionário apresenta algumas inovações no contexto deste tipo de pesquisa sobre a fraude acadêmica. Por um lado, não questiona diretamente os alunos sobre a sua prática, mas sim interroga-os sobre a gravidade que atribuem à ação de uma personagem fictícia num cenário simulado de eventual fraude. Dessa forma, o recurso a perguntas projetivas visa reduzir o risco da resposta socialmente desejável, comum em pesquisas que envolvem questionar a honestidade dos respondentes (Walker, 2010). Por outro lado, as práticas foram selecionadas com base numa teoria sobre os tipos de fraude, incluindo as diversas dimensões do conceito e evitando o reducionismo também comum a uma única dimensão como plagiar ou copiar numa prova escrita (Teixeira \& Rocha, 2010). Por fim, são incluídas no questionário perguntas sobre os motivadores da fraude e as medidas que poderão inibi-la, procurando suprir mais uma lacuna deste tipo de estudos que raramente interrogam os alunos sobre o que pensam acerca dos determinantes e inibidores da fraude acadêmica (Malgwi \& Rakovksi, 2009).

\section{Apresentação e Discussão dos Resultados}

\section{A frequência da fraude acadêmica}

O questionário incluía o questionamento aos alunos sobre a sua percepção quanto à frequência com que ocorrem, no seu curso, cada uma de 12 práticas de fraude acadêmica. A Tabela 2 apresenta a síntese desses resultados. 
Tabela 2

Frequência da Fraude Acadêmica

\begin{tabular}{|c|c|c|c|c|c|c|c|}
\hline & & & & & & & \\
\hline & $\mathrm{N}$ & Moda & Média & Nunca & Raramente & $\begin{array}{l}\text { Com alguma } \\
\text { frequência }\end{array}$ & Regularmente \\
\hline \multicolumn{8}{|c|}{ APROPRIAR } \\
\hline $\begin{array}{l}\text { Utilizar materiais não } \\
\text { autorizados na realização de } \\
\text { provas escritas. }\end{array}$ & 1253 & $\begin{array}{l}\text { Com alguma } \\
\text { frequência }\end{array}$ & 2,87 & $8 \%$ & $24,6 \%$ & $39,5 \%$ & $27,9 \%$ \\
\hline $\begin{array}{l}\text { Copiar numa prova escrita } \\
\text { pelas respostas de um colega. }\end{array}$ & 1265 & $\begin{array}{l}\text { Com alguma } \\
\text { frequência }\end{array}$ & 2,85 & $3,6 \%$ & $27,7 \%$ & $48,4 \%$ & $20,2 \%$ \\
\hline $\begin{array}{l}\text { Assinar um trabalho de grupo } \\
\text { sem ter colaborado na } \\
\text { realização do mesmo. }\end{array}$ & 1260 & $\begin{array}{l}\text { Com alguma } \\
\text { frequência }\end{array}$ & 2,70 & $13,3 \%$ & $25,5 \%$ & $39,3 \%$ & $22,0 \%$ \\
\hline $\begin{array}{l}\text { Copiar partes de trabalhos de } \\
\text { outros autores sem citá-los. }\end{array}$ & 1252 & $\begin{array}{l}\text { Com alguma } \\
\text { frequência }\end{array}$ & 2,69 & $10,5 \%$ & $27,5 \%$ & $44,4 \%$ & $17,6 \%$ \\
\hline Copiar trabalhos da Internet. & 1256 & $\begin{array}{l}\text { Com alguma } \\
\text { frequência }\end{array}$ & 2,60 & $11,6 \%$ & $31,9 \%$ & $41,3 \%$ & $15,1 \%$ \\
\hline $\begin{array}{l}\text { Copiar trabalhos de outros } \\
\text { colegas. }\end{array}$ & 1260 & $\begin{array}{l}\text { Com alguma } \\
\text { frequência }\end{array}$ & 2,54 & $12,9 \%$ & $32,5 \%$ & $42,6 \%$ & $12,0 \%$ \\
\hline $\begin{array}{l}\text { Comprar trabalhos } \\
\text { acadêmicos fora da escola. }\end{array}$ & 1242 & Raramente & 1,74 & $39,5 \%$ & $48,4 \%$ & $11,0 \%$ & $1,1 \%$ \\
\hline \multirow{2}{*}{$\begin{array}{l}\text { Comprar trabalhos de outros } \\
\text { colegas. }\end{array}$} & 1238 & Raramente & 1,70 & $43,1 \%$ & $45,6 \%$ & $9,6 \%$ & $1,7 \%$ \\
\hline & \multicolumn{6}{|c|}{ SIMULAR } & \\
\hline $\begin{array}{l}\text { Apresentar trabalhos práticos } \\
\text { com dados inventados. }\end{array}$ & 1247 & Raramente & 2,02 & $26,2 \%$ & $48,8 \%$ & $21,6 \%$ & $3,4 \%$ \\
\hline \multirow{2}{*}{$\begin{array}{l}\text { Apresentar o mesmo trabalho } \\
\text { em várias disciplinas. }\end{array}$} & 1247 & Raramente & 1,98 & $27,7 \%$ & $50 \%$ & $19,2 \%$ & $3,0 \%$ \\
\hline & \multicolumn{6}{|c|}{ FACILITAR } & \\
\hline \multirow[t]{2}{*}{$\begin{array}{l}\text { Deixar copiar respostas num } \\
\text { exame. }\end{array}$} & 1264 & $\begin{array}{l}\text { Com alguma } \\
\text { frequência }\end{array}$ & 2,71 & $5,1 \%$ & $32,8 \%$ & $47,8 \%$ & $14,3 \%$ \\
\hline & \multicolumn{5}{|c|}{ OCULTAR } & & \\
\hline $\begin{array}{l}\text { Denunciar fraudes } \\
\text { acadêmicas cometidas por } \\
\text { colegas. }\end{array}$ & 1255 & Nunca & 1,36 & $67,2 \%$ & $30,0 \%$ & $2,5 \%$ & $0,3 \%$ \\
\hline
\end{tabular}

As respostas revelam que a prática mais comum é utilizar materiais não autorizados na realização de provas escritas, seguida de copiar numa prova escrita pelas respostas de um colega e de assinar um trabalho de grupo sem ter colaborado na realização do mesmo. As práticas que ocorrem menos frequentemente são comprar trabalhos de outros colegas e comprar trabalhos acadêmicos fora da escola, com destaque para a quase ausência da prática de denunciar fraudes acadêmicas cometidas por colegas estudantes.

Estes resultados sugerem que as formas clássicas de fraude, em sala de exame ou durante as aulas, mantêm-se como as mais frequentes na percepção dos alunos. A compra de trabalhos é rara nesse caso dos cursos de administração e de economia, e parece prevalecer uma cultura de tolerância perante a fraude dos colegas, talvez justificada pela cumplicidade que legitima o ato ou que permite a reciprocidade. Se analisadas por tipo de fraude, as práticas fraudulentas de apropriação e facilitação 
são mais frequentes do que a simulação. Curiosamente, as mulheres consideram a fraude mais frequente do que os homens.

\section{A gravidade da fraude acadêmica}

Os nove cenários incluíam nove práticas ativas - de apropriação ou simulação - e quatro práticas passivas - de facilitação da apropriação. Sobre todas elas, era requerido ao aluno que se pronunciasse quanto à sua gravidade e que respondesse se faria o mesmo se estivesse naquela situação. Também era perguntado ao aluno se denunciaria cada uma das nove práticas ativas. Os resultados são apresentados na Tabela 3 .

Tabela 3

\section{Gravidade da Fraude Acadêmica}

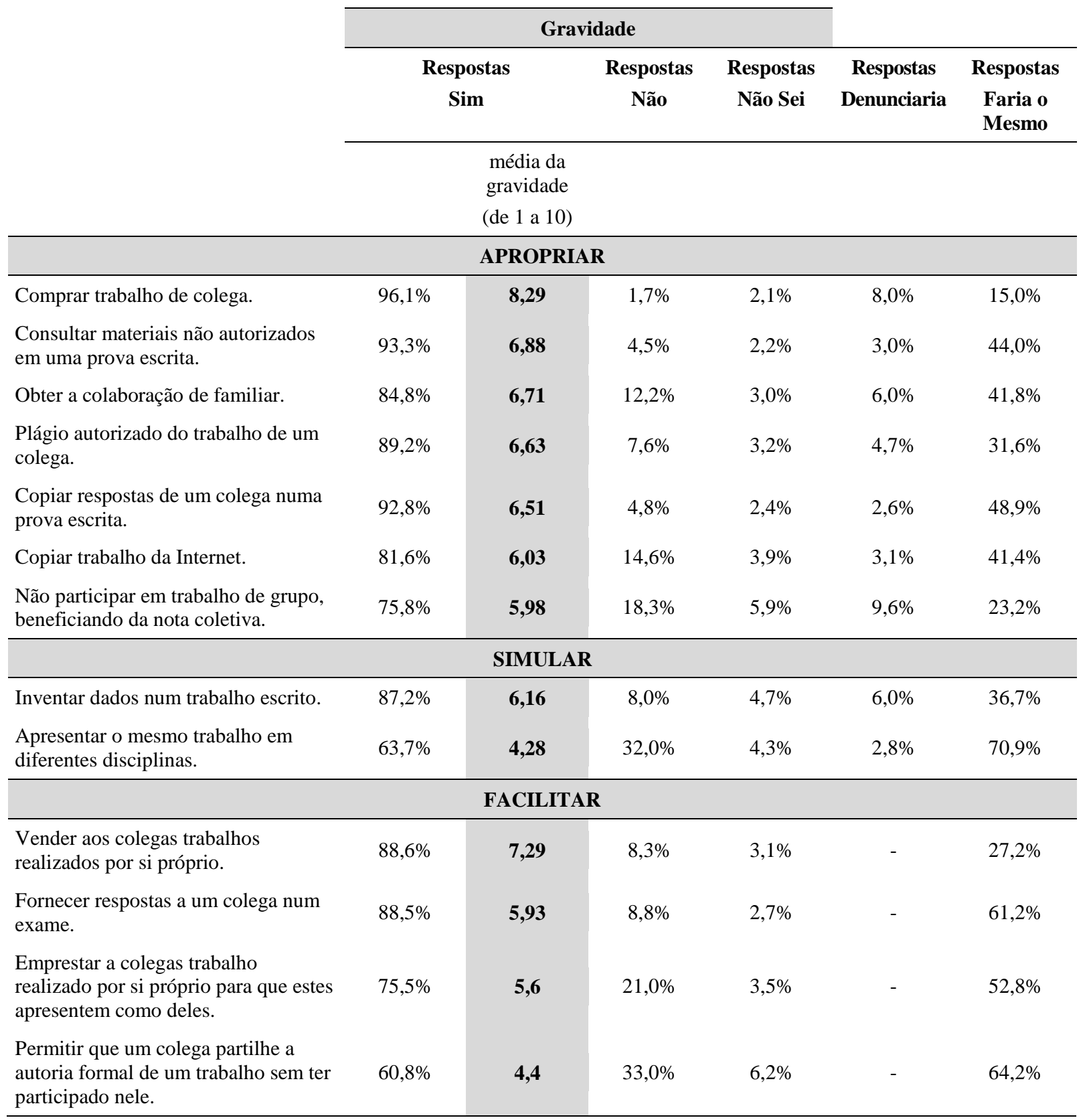


Os resultados destacam como práticas mais graves a compra e a venda de trabalhos, o recurso a materiais não autorizados durante as provas escritas e a colaboração de um familiar para realizar um trabalho em nome do aluno. As práticas menos graves incluem apresentar o mesmo trabalho em diferentes disciplinas e permitir que um colega partilhe a autoria formal de um trabalho sem ter participado nele (são também as práticas que mais alunos consideraram não ser fraude), o que parece revelar uma legitimação da fraude, desde que não represente apropriação do trabalho alheio ou obtenção de benefício por fonte externa ao processo pedagógico e estranha à rede de relações baseada na cumplicidade acadêmica.

Os dados sugerem que os métodos de avaliação baseados em trabalhos de grupo criam condições para práticas de fraude que os alunos tendem a não condenar ou a atribuir baixa gravidade. Mas isto é moderado pela forma como a fraude é cometida: se implicar transação econômica é claramente condenada; se for no âmbito das relações habituais de cumplicidade e de reciprocidade acadêmica, é menos grave. Parece existir aqui um princípio moral (a solidariedade não mercantil) que visa atenuar ou regularizar a fraude acadêmica e a sua gravidade.

Com vista a avaliar como os alunos organizam mentalmente as práticas de fraude de acordo com a sua gravidade, foi realizada uma análise fatorial exploratória dos dados. Os resultados sugerem que as práticas de fraude estão relacionadas entre si por um critério que não necessariamente aquele que decorre da tipologia proposta, tendo distinguido 3 fatores que explicam 64,63\% da variância total (KMO 0,863; Teste de Esfericidade de Bartlett com p-valor 0,000): fraude durante um exame escrito, fraude na realização e nos trabalhos e fraude baseada em transação econômica ou afetiva.

Os alunos parecem assim distinguir a gravidade das práticas de fraude consoante o tipo de avaliação em causa: exame ou trabalho (individual ou de grupo, como, por exemplo, monografias, projetos ou apresentação de aulas). É, no entanto, interessante verificar que, quando está em causa o recurso a uma transação econômica ou afetiva (com base em relação familiar), os alunos distinguem a gravidade da transgressão, ou seja, talvez prevaleça entre os alunos uma condenação da fraude cometida com recurso a vantagens sociais e econômicas que são diferenciadas na medida em que só estão ao alcance de alguns. Assim, para atribuir gravidade às práticas de fraude, os alunos parecem usar como critério, para além da instância de avaliação, e talvez acima dela, a acessibilidade a oportunidades de cometer fraude - que pode ser facilitada ou dificultada pelas condições econômicas ou pelo contexto cultural de cada aluno.

\section{Os índices de predisposição para a fraude e para a denúncia (IPF e IPD)}

Com base nos dados obtidos, é possível construir um indicador que permite avaliar a propensão do aluno para cometer fraude acadêmica (o Índice de Predisposição para a Fraude [IPF]) e um indicador que permite avaliar a sua propensão para denunciar a fraude observada (o Índice de Predisposição para a Denúncia [IPD]). Esses indicadores são uma inovação deste estudo, possível devido à forma como foi construído o questionário, e revelam-se especialmente interessantes para avaliar os determinantes da propensão para a fraude e também para analisar com maior pertinência a opinião dos alunos sobre os motivadores e, mais ainda, os inibidores. O IPF de cada aluno corresponde ao número de vezes que respondeu positivamente à pergunta sobre se faria o mesmo que o transgressor em cada cenário de fraude. Como os cenários incluíam 13 práticas, o IPF varia entre 0 e 13, sendo que, quanto maior for o IPF, maior será a propensão do aluno para cometer fraude acadêmica. O IPD de cada aluno corresponde ao número de vezes que respondeu que denunciaria a situação caso tivesse conhecimento dela em cada cenário de fraude. Neste caso, não se distingue a posição ativa da posição passiva, mas apenas os cenários de fraude que as incluem, por isso, o IPD varia entre 0 e 9 , sendo que, quanto maior for o IPD, maior será a propensão do aluno para denunciar a fraude acadêmica que observar.

Para facilitar a comparação, a escala dos indicadores IPF e IPD sofreu uma transformação linear para que ambos tenham uma variação entre 0 e 10. 
Tabela 4

\section{Índice de Predisposição para a Fraude (IPF) e Índice de Predisposição para a Denúncia (IPD) - Caracterização}

\begin{tabular}{|c|c|c|c|c|c|c|}
\hline & \multirow{2}{*}{\multicolumn{3}{|c|}{$\begin{array}{c}\text { Índice de Predisposição para a } \\
\text { Fraude }\end{array}$}} & \multirow{2}{*}{\multicolumn{3}{|c|}{$\begin{array}{c}\text { Índice de Predisposição para a } \\
\text { Denúncia }\end{array}$}} \\
\hline & & & & & & \\
\hline & $\begin{array}{c}\text { Média } \\
\text { (entre } 0 \text { e } 10)\end{array}$ & $\mathrm{t}$-diferença & p-valor & $\begin{array}{c}\text { Média } \\
\text { (entre } 0 \text { e } 10)\end{array}$ & $\mathrm{t}$-diferença & p-valor \\
\hline Todos os alunos & 4,02 & & & $\mathbf{0 , 5 0}$ & & \\
\hline $\begin{array}{l}\text { Alunos que consideram a fraude } \\
\text { aceitável. }\end{array}$ & 5,50 & \multirow[b]{2}{*}{19,972} & \multirow[b]{2}{*}{0,000} & 0,66 & \multirow[b]{2}{*}{3,469} & \multirow[b]{2}{*}{0,001} \\
\hline $\begin{array}{l}\text { Alunos que consideram a fraude } \\
\text { inaceitável. }\end{array}$ & 2,79 & & & $\mathbf{0 , 3 7}$ & & \\
\hline Alunos sexo masculino & 4,33 & \multirow{2}{*}{3,487} & \multirow{2}{*}{0,001} & 1,46 & \multirow{2}{*}{0,144} & \multirow{2}{*}{0,886} \\
\hline Alunos sexo feminino & 3,82 & & & 1,36 & & \\
\hline $\begin{array}{l}\text { Alunos cujo curso que } \\
\text { frequentam é primeira escolha. }\end{array}$ & 3,91 & \multirow[b]{2}{*}{2,909} & \multirow[b]{2}{*}{0,004} & 0,54 & \multirow[b]{2}{*}{2,105} & \multirow[b]{2}{*}{0,036} \\
\hline $\begin{array}{l}\text { Alunos cujo curso que } \\
\text { frequentam não é primeira } \\
\text { escolha. }\end{array}$ & 4,39 & & & $\mathbf{0 , 3 7}$ & & \\
\hline Alunos que já reprovaram. & 4,11 & \multirow[b]{2}{*}{2,341} & \multirow[b]{2}{*}{0,019} & 0,46 & \multirow[b]{2}{*}{1,750} & \multirow[b]{2}{*}{0,081} \\
\hline $\begin{array}{l}\text { Alunos que ainda não } \\
\text { reprovaram. }\end{array}$ & 3,37 & & & 0,65 & & \\
\hline $\begin{array}{l}\text { Alunos que afirmam existir } \\
\text { código de boas práticas ou } \\
\text { regulamento. }\end{array}$ & 3,75 & \multirow{2}{*}{3,001} & \multirow{2}{*}{0,003} & 0,52 & \multirow{2}{*}{1,854} & \multirow[b]{2}{*}{0,072} \\
\hline $\begin{array}{l}\text { Alunos que afirmam não existir } \\
\text { código de boas práticas ou } \\
\text { regulamento. }\end{array}$ & 5,19 & & & 0,25 & & \\
\hline $\begin{array}{l}\text { Alunos que afirmam ter lido o } \\
\text { código de boas práticas ou } \\
\text { regulamento. }\end{array}$ & 3.12 & \multirow[b]{2}{*}{4,469} & \multirow[b]{2}{*}{0,000} & $\mathbf{0 , 8 1}$ & \multirow[b]{2}{*}{2,638} & \multirow[b]{2}{*}{0,009} \\
\hline $\begin{array}{l}\text { Alunos que ainda não leram o } \\
\text { código de boas práticas ou } \\
\text { regulamento. }\end{array}$ & 4.12 & & & $\mathbf{0 , 3 9}$ & & \\
\hline
\end{tabular}

Como se pode observar na Tabela 4, o IPF da amostra apresenta uma média geral de 4,02, sendo significativamente maior entre os alunos que consideram a fraude aceitável em determinadas circunstâncias (IPF 5,5) do que entre aqueles que a consideram sempre inaceitável (IPF 2,79). A análise das relações estatisticamente significativas entre o IPF e as condições sociodemográficas e acadêmicas dos alunos revelou que a propensão para cometer fraude é maior nos homens (IPF 4,33) do que nas mulheres (IPF 3,82), bem como é maior nos alunos cujo curso e a instituição que frequentam não foi a sua primeira escolha e que já reprovaram em alguma disciplina. Por fim, o IPF é também mais elevado em alunos que afirmam não existir código de boas práticas ou um regulamento disciplinar formal na sua escola, ou de entre os que afirmam existir regulamento, que ainda não o leram, o que sugere, neste caso, a influência do contexto institucional.

O IPF também aumenta à medida que aumenta o número de disciplinas que o aluno reprovou (correlação de Spearman 0,098 p-valor 0,004), e a média de curso diminui (correlação de Spearman 0,081, p-valor 0.005). Esses resultados sugerem que a eventual falta de identificação com o curso que 
se frequenta e o insucesso acadêmico (ambos porventura relacionados entre si) descomprometem o aluno com uma conduta honesta. Além desses fatores pessoais, o IPF também aumenta de forma estatisticamente significativa à medida que aumenta a percepção sobre a frequência da fraude cometida por colegas (correlação de Spearman 0,199, p-valor 0.004), o que sugere a influência também decisiva dos contextos cultural e institucional.

No caso do IPD, a média geral da amostra é de 0,50 , sendo significativamente maior entre os alunos que consideram a fraude inaceitável (IPD 0,66) do que entre aqueles que a consideram aceitável em determinadas circunstâncias (IPD 0,37). Os dados revelam apenas uma maior propensão para denunciar a fraude por parte de alunos cujo curso que frequentam foi a primeira escolha, que ainda não reprovaram e que afirmam existir código de boas práticas ou regulamento disciplinar, e também entre aqueles que conhecem o seu conteúdo.

A análise de correlação revela que a propensão para a denúncia é maior entre os alunos que têm menos inscrições no ensino superior (correlação de Spearman -0,079, p-valor 0.005) e médias mais elevadas (correlação de Spearman -0,076 p-valor 0.007). Esses dados revelam o peso da cultura organizacional e da cultura de pares na normalização de uma determinada cultura de fraude. Se a predesposição para a denúncia é maior à chegada e se diminui à medida que os alunos têm uma maior integração nas instituições, o convívio com práticas de fraude baseadas na solidariedade entre pares (por exemplo, dar uma carona hoje na realização de um trabalho e receber em troca amanhã) legitima e naturaliza aquelas formas de fraude de que todos podem se beneficiar. Já a maior aversão dos melhores alunos à fraude acadêmica, que torna a opção pela transgressão uma prática inaceitável e condenável, pode ser vista como reflexo de um percurso escolar mais comprometido com o curso e com a instituição.

\section{Os motivos da fraude acadêmica}

Os alunos foram também questionados sobre quais os motivos que, na sua opinião, levam os estudantes a cometerem fraude. Na Tabela 5 é apresentada uma síntese dos resultados, incluindo a média das respostas para cada motivo e a correlação destes com o IPF e o IPD.

Tabela 5

Importância dos Motivos de Fraude Acadêmica e sua Correlação com IPF e IPD

\begin{tabular}{lccc} 
& \multicolumn{2}{c}{ Média } & \multicolumn{2}{c}{ Correlação } \\
\cline { 2 - 4 } & (importância de 1 a 5) & IPF & IPD \\
\hline Segurança de sucesso numa disciplina em que já se reprovou & $\mathbf{3 , 6 8}$ & $0,190^{* *}$ & $-0,005$ \\
Carga de trabalho acadêmico & $\mathbf{3 , 6 0}$ & $0,210^{* *}$ & $-0,014$ \\
$\begin{array}{l}\text { Insegurança sobre a capacidade de alcançar o sucesso de outra } \\
\text { forma }\end{array}$ & $\mathbf{3 , 2 7}$ & $0,103^{* *}$ & $-0,039$ \\
Hábito de uma conduta fraudulenta desde o ensino médio & $\mathbf{3 , 1 0}$ & $-0,087^{* *}$ & 0,024 \\
Modalidades de avaliação & $\mathbf{3 , 0 5}$ & $0,114^{* *}$ & 0,053 \\
Pouca relevância prática atribuída aos conteúdos curriculares & $\mathbf{2 , 9 8}$ & $0,061^{*}$ & 0,017 \\
Regularidade da prática fraudulenta entre colegas & $\mathbf{2 , 8 5}$ & $-0,025$ & 0,003 \\
\hline
\end{tabular}




\section{Tabela 5 (continuação)}

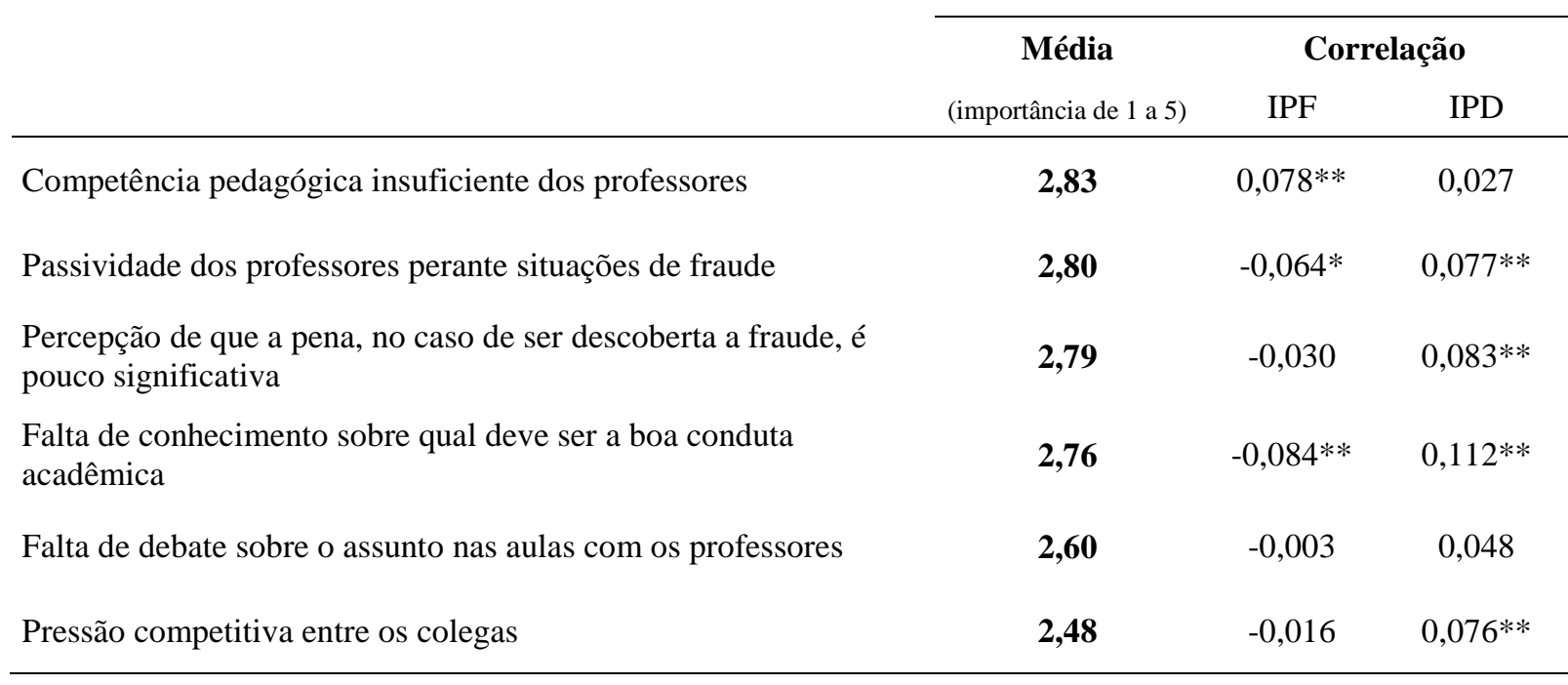

Nota. * sig. 0,$05 ; * *$ sig. 0,001 .

Como pôde ser observado, na opinião dos alunos, os motivos mais relevantes estão relacionados com os obstáculos para alcançar êxito acadêmico de outra forma, quer sejam as características do curso ou a insegurança do aluno. Os alunos que reconhecem a carga de trabalho acadêmico e a experiência passada de reprovação à disciplina como principais motivos para cometer fraude, tendem a apresentar um IPF mais elevado, desvalorizando a ignorância sobre os princípios de boa conduta e o hábito de práticas de fraude como motivos para cometê-la. Isto parece sugerir uma responsabilização prioritária atribuída pelos alunos aos níveis de exigência pedagógica de cada curso como motivadores de fraude.

Por outro lado, os alunos parecem estar mais dispostos a denunciar a fraude e a combatê-la (IPD mais elevado) quando reconhecem que a ignorância e a impunidade conduzem a práticas fraudulentas. Pode haver aqui uma sugestão de que o aluno se sente compelido a substituir a instituição no combate à fraude (porque a instituição não informa sobre ela, não a fiscaliza ou não a pune adequadamente).

Com vista a estudar se existem categorias de motivos para cometer fraude, segundo a importância que os alunos lhes atribuem, foi realizada uma análise fatorial exploratória dos dados, a qual permitiu agrupar os motivos em quatro fatores, tal como apresentados na Tabela 6. Este agrupamento de motivos pode ajudar a compreender melhor as raízes do fenômeno e os seus fundamentos psicológicos.

Tabela 6

Motivos da Fraude Acadêmica (Análise Fatorial Exploratória)

\begin{tabular}{cccc}
\hline \multicolumn{4}{c}{ Componentes } \\
\hline $\mathbf{1}$ & $\mathbf{2}$ & $\mathbf{3}$ & $\mathbf{4}$ \\
\hline & & & 0,824 \\
& & & 0,738
\end{tabular}

Insegurança sobre a capacidade de alcançar o sucesso de outra forma

0,536

Falta de conhecimento sobre qual deve ser a boa conduta acadêmica

0,763

Hábito de uma conduta fraudulenta desde o ensino médio 


\section{Tabela 6 (continuação)}

\begin{tabular}{lcc} 
& \multicolumn{1}{c}{ Componentes Principais $^{\mathrm{a}}$} \\
\cline { 2 - 3 } & $\mathbf{1}$ & $\mathbf{2}$ \\
\hline Falta de debate sobre o assunto nas aulas com os professores & 0,540 & 0,562 \\
Segurança de sucesso numa disciplina que já se reprovou & 0,765 \\
Regularidade da prática fraudulenta entre colegas & 0,650 \\
Passividade dos professores perante situações de fraude & 0,722 \\
Carga de trabalho acadêmico & 0,643 \\
Pouca relevância prática atribuída aos conteúdos curriculares & 0,751 \\
Modalidades de avaliação & 0,581 \\
Competência pedagógica insuficiente dos professores & \\
Percepção de que a pena, no caso de ser descoberta a fraude, é pouco \\
significativa
\end{tabular}

Nota. KMO 0,782; Teste de Esfericidade de Bartlett com p-valor 0,000; retidos 4 fatores com base na sugestão do screeplot (variância explicada de $57,73 \%$ ).

a apenas incluídos pesos superiores a 0,5 .

Os fatores identificados surgem organizados segundo um critério aparentemente relacionado com as diferentes instâncias com as quais o aluno se relaciona, distinguindo o círculo interior da relação consigo mesmo e com os colegas, de um círculo intermédio da relação com cada professor e cada disciplina, até ao círculo exterior da relação com a instituição. Assim, os fatores podem ser classificados nos seguintes termos:

\section{Fator 1 - políticas dissuasoras (nível institucional)}

\section{Fator 2 - práticas pedagógicas (nível da disciplina)}

\section{Fator 3 - cultura de fraude (nível da relação entre colegas)}

\section{Fator 4 - pressão para o êxito (nível individual)}

Esse arranjo da forma como os alunos organizam os motivos de fraude, em termos da sua importância, sugere que talvez seja possível, em boa medida, combater a fraude com políticas institucionais dirigidas a aspetos concretos da política pedagógica.

\section{Os inibidores da fraude acadêmica}

Foi igualmente perguntado aos alunos quais os fatores que poderiam, na sua opinião, inibir a prática de fraude acadêmica. Quando comparadas as médias das importâncias atribuídas aos inibidores pelos alunos que consideram a fraude aceitável em determinadas circunstâncias (grupo utilitarista) e os alunos que a consideram sempre inaceitável (grupo deontológico), o resultado revela que existe uma diferença significativa entre esses dois grupos de alunos (médias 2,82 e 3,06, respetivamente). Esse resultado sugere que se analise, além da opinião geral, também as médias de respostas de cada um dos grupos de alunos. A Tabela 7 apresenta tais resultados agregados. 
Tabela 7

Importância dos Inibidores de Fraude Acadêmica e sua Correlação com o IPF e o IPD

\begin{tabular}{|c|c|c|c|c|c|}
\hline & \multicolumn{3}{|c|}{$\begin{array}{c}\text { Média } \\
\text { (importância de 1 a 5) }\end{array}$} & \multicolumn{2}{|c|}{ Correlação } \\
\hline & Total & Aceitável & Inaceitável & IPF & IPD \\
\hline $\begin{array}{l}\text { Agravamento das penas para conduta acadêmica } \\
\text { fraudulenta }\end{array}$ & 3,39 & 3,16 & 3,64 & $-0,111^{* *}$ & $0,062 *$ \\
\hline $\begin{array}{l}\text { Existência de uma relação de proximidade entre } \\
\text { professores e alunos }\end{array}$ & 3,32 & 3,42 & 3,27 & $0,084 * *$ & \\
\hline $\begin{array}{l}\text { Envolvimento dos estudantes na divulgação de boas } \\
\text { práticas acadêmicas }\end{array}$ & 3,14 & 3,04 & 3,25 & $-0,087 * *$ & $0,099 * *$ \\
\hline $\begin{array}{l}\text { Inpedimento de celulares ligados na sala onde se } \\
\text { realizam exames. }\end{array}$ & 3,14 & 2,91 & 3,35 & $-0,101 * *$ & \\
\hline $\begin{array}{l}\text { Utilização de mecanismos de vigilância e de deteção } \\
\text { eletrônica de fraude }\end{array}$ & 3,09 & 2,94 & 3,29 & $-0,066^{*}$ & \\
\hline $\begin{array}{l}\text { Frequência de programas de desenvolvimento de } \\
\text { competências acadêmicas }\end{array}$ & 3,06 & 3,08 & 3,14 & $-0,056^{*}$ & \\
\hline Frequência de programas de apoio psicopedagógico & 2,97 & 2,96 & 3,04 & $-0,083 * *$ & \\
\hline $\begin{array}{l}\text { Garantia de anonimato na denúncia de } \\
\text { comportamentos fraudulentos dos colegas }\end{array}$ & 2,91 & 2,75 & 3,17 & $-0,142 * *$ & $0,133 * *$ \\
\hline Divulgação de um Código de Conduta da escola & 2,82 & 2,58 & 3,05 & $-0,197 * *$ & $0,091 * *$ \\
\hline $\begin{array}{l}\text { Entrega de uma declaração de autoria/originalidade } \\
\text { dos trabalhos apresentados para avaliação }\end{array}$ & 2,78 & 2,73 & 2,93 & $-0,127 * *$ & $0,087 * *$ \\
\hline $\begin{array}{l}\text { Sessões de esclarecimento promovidas pela escola } \\
\text { sobre a boa conduta acadêmica }\end{array}$ & 2,70 & 2,60 & 2,83 & $-0,135^{* *}$ & $0,076^{* *}$ \\
\hline Frequência de disciplinas sobre Ética & 2,55 & 2,38 & 2,72 & $-0,196^{* *}$ & $0,086 * *$ \\
\hline $\begin{array}{l}\text { Divulgação no ambiente escolar do nome dos alunos } \\
\text { que praticaram fraudes }\end{array}$ & 2,54 & 2,45 & 2,76 & $-0,084 * *$ & $0,100 * *$ \\
\hline Existência de provas orais obrigatórias & 2,41 & 2,46 & 2,40 & $0,087 * *$ & \\
\hline
\end{tabular}

Nota. *p-valor 0,05 (correlação de Spearman); ** p-valor 0,001 (correlação de Spearman).

Segundo os alunos, os principais inibidores da fraude são o agravamento da pena e a proximidade da relação com os professores, seguindo-se práticas de maior envolvimento dos alunos com a instituição e reforço dos mecanismos dissuasores. Apesar do caráter punitivo do agravamento das penas, os resultados parecem sugerir que a relação de proximidade entre aluno e instituição pode efetivamente desincentivar a fraude. Por outro lado, o esclarecimento sobre a boa conduta e as provas orais obrigatórias não parecem surtir um efeito dissuasor significativo. Curiosamente, a divulgação pública do nome dos transgressores parece não ser vista como um castigo desincentivador da transgressão. Quando analisada apenas a opinião dos alunos potencialmente mais transgressores (que consideram aceitável a fraude), verifica-se que as grandes hierarquias de importância se mantêm, com um reforço dos mecanismos dissuasores. Também para esses alunos, a relação de proximidade com os professores tem um elevado potencial desincentivador. Talvez subjacente a esta opinião exista uma queixa quanto ao distanciamento relacional entre professor e aluno que as novas políticas educativas parecem não ter ainda conseguido combater ${ }^{(2)}$. 
Tal como esperado, o IPF varia negativamente com a importância atribuída a quase todos os potenciais inibidores da fraude, confirmando esses como efetivos potenciais desincentivadores da transgressão. Neste caso, o IPD sugere um caminho mais específico, uma vez que alunos com maior IPD consideram como inibidores significativos iniciativas que promovam uma cultura institucional de intolerância à fraude que legitime e incentive a denúncia.

A análise fatorial dos dados permitiu agrupar os inibidores em 3 fatores, tal como apresentados na Tabela 8 (a mesma análise para as amostras do grupo utilitarista e do grupo deontológico produziu resultado idêntico, sugerindo a universalidade da interpretação desses fatores).

Tabela 8

Inibidores da Fraude Acadêmica (Análise Fatorial Exploratória)

\begin{tabular}{lcc} 
& \multicolumn{1}{c}{ Componentes Principais $^{\text {a }}$} \\
\cline { 2 - 2 } Divulgação de um Código de Conduta da escola & $\mathbf{1}$ & $\mathbf{2}$ \\
\hline Frequência de disciplinas sobre Ética & 0,823 \\
Agravamento das penas para conduta acadêmica fraudulenta & 0,740 \\
Utilização de mecanismos de vigilância e de deteção eletrônica de fraude & 0,815 \\
Impedimento de celulares ligados na sala onde se realizam exames & 0,671 \\
Existência de provas orais obrigatórias & 0,536
\end{tabular}

Existência de uma relação de proximidade entre professores e alunos

Envolvimento dos estudantes na divulgação de boas práticas acadêmicas

Sessões de esclarecimento promovidas pela escola sobre a boa conduta acadêmica

Divulgação no ambiente escolar do nome dos alunos que praticaram fraudes

Entrega de uma declaração de autoria/originalidade dos trabalhos apresentados para avaliação

Garantia de anonimato na denúncia de comportamentos fraudulentos dos colegas

Frequência de programas de apoio psicopedagógico

Frequência de programas de desenvolvimento de competências acadêmicas

Nota. KMO 0,822; Teste de Esfericidade de Bartlett com p-valor 0,000; retidos 3 fatores com base na sugestão do screeplot (variância explicada de 56,48\%).

a apenas incluídos pesos superiores a 0,5 .

De acordo com os resultados, o agrupamento dos inibidores parece ter como critério de diferenciação entre eles o tipo de estratégia institucional de combate à fraude, podendo os 3 fatores ser classificados nos seguintes termos:

Fator 1 - Estratégias de dissuasão

Fator 2 - Estratégias de informação

Fator 3 - Estratégias de apoio pedagógico 
A organização dos inibidores nestes 3 fatores sugere que existem três eixos possíveis de organização do combate institucional à fraude. Um primeiro, que privilegia a criação e o desenvolvimento de mecanismos de dissuasão, baseados num sistema de denúncia e castigo da fraude acadêmica. Um segundo que privilegia estratégias de formação e informação dos alunos sobre a boa conduta acadêmica. E um terceiro, que privilegia a qualidade da relação pedagógica com o aluno, materializada em políticas de reforço da proximidade e do comprometimento do aluno com a instituição.

\section{Conclusão}

A fraude acadêmica é um problema social e institucional, dados os efeitos nocivos e multiplicadores que pode ter no mercado de trabalho e a forma como pode comprometer a confiança nas instituições e, portanto, o progresso coletivo da sociedade. As universidades parecem ainda mal preparadas para lidar eficazmente com o plágio e a fraude acadêmica (Sutherland-Smith, 2010). Os docentes, agentes primários da permissão ou desincentivo da fraude, mostram sinais de interesse e empenho neste processo, mas ainda estão aparentemente desvinculados das políticas institucionais (Jager \& Brown, 2010). No caso da fraude cometida por futuros administradores, executivos e economistas, o estudo do fenômeno apresenta-se particularmente relevante, dadas as implicações sociais profundas que as escolhas destes decisores podem implicar. Assim, o objetivo deste estudo exploratório consistiu em analisar a atitude dos alunos de administração, economia e áreas afins perante a fraude acadêmica, a sua opinião sobre a gravidade dos diferentes tipos de fraude, o que a motiva e o que a poderá inibir. Para fazê-lo, propôs-se uma tipologia de fraude acadêmica decomposta em quatro dimensões - apropriação, simulação, facilitação e ocultação. Empiricamente, foram inquiridos por questionário fechado, presencial, 1276 estudantes de instituições portuguesas de ensino superior. $\mathrm{O}$ instrumento de coleta de dados foi previamente validado e apresenta três inovações principais: é projetivo, questiona diversas dimensões de fraude e inclui questões sobre os motivadores e os inibidores de fraude.

Os resultados revelaram que utilizar materiais não autorizados na realização de provas escritas é a prática de fraude acadêmica mais comum, sendo de destacar a significativa quase a ausência da denúncia de fraudes acadêmicas cometidas por colegas, o que parece sugerir a prevalência, entre os alunos de administração e de economia, de uma cultura dominante de tolerância à transgressão. Em relação à gravidade dos tipos de fraude praticados, os alunos parecem atribuir gravidade à fraude em função do tipo de avaliação que ela corrompe (distingue-se, neste caso, a fraude cometida durante exame escrito da fraude cometida na realização de trabalhos, sendo isolada e destacada pelos alunos a extrema gravidade de cometer fraude baseada numa transação econômica ou afetiva).

No âmbito desta pesquisa foram igualmente propostos dois novos indicadores que avaliam a predisposição para a fraude (IPF) e a predisposição para a denúncia (IPD). Do ponto de vista sociodemográfico e acadêmico, a análise desses indicadores sugeriu que a propensão para cometer fraude é maior entre os piores alunos e entre aqueles que não se identificam com o curso, o que constitui um resultado novo em relação às dimensões pessoais habitualmente estudadas. A análise sugere também que a percepção de que a fraude é uma prática comum no ambiente acadêmico próximo induz à propensão para cometê-la (efeito de contágio cultural). Por outro lado, a inexistência de um código de boas práticas acadêmicas ou de um regulamento formal, talvez pelo efeito de tolerância institucional que sugere, está associada a uma predisposição maior para a fraude. Esses resultados evidenciam a importância da divulgação e da aplicação sancionatória de instrumentos formais das instituições de ensino para combate à fraude e pedagogia de boas práticas. Por fim, o estudo revela que os principais motivos que levam os estudantes a cometer fraude estão relacionados com a dificuldade das matérias e das condições pedagógicas, e que o fator inibidor ao qual os estudantes atribuem, em média, maior importância, é o agravamento das penas para conduta acadêmica fraudulenta. 
No contexto universitário, a transgressão dos alunos é um indicador do seu potencial transgressor futuro e, no caso particular das escolas de administração e de economia, um sinalizador relevante da predisposição moral destes futuros decisores organizacionais para lidar com os dilemas da sua profissão, os quais têm frequentemente profundas implicações sociais. Os estudos sobre esse tipo de fraude sugerem que ela tem vindo a aumentar em todo o mundo, favorecida pelo uso de novas tecnologias e legitimada por culturas institucionais tolerantes à fraude. Esta pesquisa parece confirmar essas tendências e apresenta-se como mais uma contribuição, com recurso a métodos aprofundados de pesquisa quantitativa, para o debate em torno das práticas transgressoras dos alunos e do papel das instituições de ensino na facilitação ou no combate a essas práticas.

\section{Notas}

\footnotetext{
${ }^{1}$ Texto produzido no âmbito do projeto de investigação A ética dos alunos e a tolerância de professores e instituições perante a fraude académica no ensino superior, financiado pela Fundação para a Ciência e a Tecnologia - PTDC/CPECED/115915/2009).

${ }^{2}$ Sendo raros e circunscritos a determinadas instituições, estudos realizados no Brasil, como, por exemplo a pesquisa de Pimenta, M. A. A. (2010). Fraude em avaliações na visão de professores e de estudantes: uma reflexão sobre formação profissional e ética. Revista Profissão Docente, 10(22), 124-138, junto de 250 alunos e de 54 professores, corroboram tendências observadas com nossa pesquisa. Outros estudos, como, por exemplo, Caballero, A. J. D., Martínez, F. D. G., \& Arango, L. E. C. (2010). Relación del fraude académico con situaciones personales que enfrentan los estudiantes en la Facultad de Odontología de la Universidad de Cartagena (Colombia). Revista Salud Uninorte, 26(1), 85-97, reportando-se a realidades latino-americanas, relevam um fator de fraude não identificado em nossa pesquisa, designadamente a prevalência da fraude junto dos alunos oriundos de meios sociais mais desfavorecidos.
}

\section{Referências}

Almeida, F. J. R. de (2007). Ética e desempenho social das organizações: um modelo teórico de análise dos fatores culturais e contextuais. Revista de Administração Contemporânea, 11(3), 105-125. doi: 10.1590/S1415-65552007000300006

Almeida, F. J. R. de, Gama, P., \& Peixoto, P. (2010). La ética de los alumnos de la enseñanza superior: un estudio exploratorio sobre el fraude acadêmico en Portugal [Working Paper $n^{\circ}$ 348]. Oficina do CES, Centro de Estudos Sociais, Coimbra, Portugal.

Bazerman, C. (2010). Paying the rent: languaging particularity and novelty. Revista Brasileira de Linguística Aplicada, 10(2), 459-469. doi: 10.1590/S1984-63982010000200010

Brandt, D. (2002). Copyright's (not so) little cousin, plagiarism. Computers in Libraries, 22(5), 39-42.

Bunn, D. N., Caudill, S. B., \& Gropper, D. M. (1992). Crime in the classroom: an economic analysis of undergraduate student cheating behavior. Journal of Economic Education, 23(3), 197-207.

Callahan, D. (2004). The cheating culture: why more Americans are doing wrong to get ahead. Florida, USA: Hartcourt Books

Crittenden, V. L., Hanna, R. C., \& Peterson, R. A. (2009). The cheating culture: a global societal phenomenon. Business Horizons, 52(4), 337-346. doi: 10.1016/j.bushor.2009.02.004

Gomes, L. L. Z. (2011). Internet; instrumento de plágio ou instrumento de pesquisa? Revista Triângulo, 4(1), 1-10. 
Hrabak, M., Vujaklija, A., Vodopivec, I., Hren, D., Marusic, M., \& Marusic, A. (2004). Academic misconduct among medical students in a postcommunist country. Medical Education, 38(3), 276-285.

Jager, K. de, \& Brown, C. (2010). The tangled web: investigating academics' views of plagiarism at the University of Cape Town. Studies in Higher Education, 35(5), 513-528. doi: $10.1080 / 03075070903222641$

Lawson, R. A. (2004). Is classroom cheating related to business student's propensity to cheat in the "real world"? Journal of Business Ethics, 49(2), 189-199. doi: 10.1023/B:BUSI.0000015784.34148.cb

Malgwi, C. A., \& Rakovski, C. C. (2009). Combating academic fraud: are students reticent about uncovering the covert? Journal of Academic Ethics, 7(3), 207-221. doi: 10.1007/s10805-0099081-4

Marsden, H., Carroll, M., \& Neill, J. T. (2005). Who cheats at university? A self-report study of dishonest academic behaviours in a sample of Australian university students. Australian Journal of Psychology, 57(1), 1-10. doi: 10.1080/00049530412331283426

Mayhew, M. J., Seifert, T. A., \& Pascarella, E. T. (2010). A multi-institutional assessment of moral reasoning development among first-year students. Review of Higher Education, 33(3), 357-390. doi: $10.1353 /$ rhe.0.0153

McCabe, D. (1999). Academic dishonesty among high school students. Adolescence, 139(34), 681687.

McCabe, D. (2009). Academic dishonesty in nursing schools: an empirical investigation. Journal of Nursing Education, 48(11), 614-623.

McCabe, D. L., Butterfield, K. D., \& Treviño, L. K. (2003). Faculty and academic integrity: the influence of current honor codes and past honor code experiences. Research in Higher Education, 44(3), 367-385. doi: 10.1023/A:1023033916853

McCabe, D. L., Butterfield, K. D., \& Treviño, L. K. (2006). Academic dishonesty in graduate business programs: prevalence, causes, and proposed action. Academy of Management Learning \& Education, 5(3), 294-305. doi: 10.5465/AMLE.2006.22697018

McCabe, D. L., Treviño, L. K., \& Butterfield, K. D. (2001). Cheating in academia institutions: a decade of research. Ethics \& Behavior, 11(3), 219-232. doi: 10.1207/S15327019EB1103_2

McCabe, D. L., Treviño, L. K., \& Butterfield, K. D. (2002). Honor codes and other contextual influences on academic integrity: a replication and extension to modified honor code settings. Research in Higher Education, 43(3), 357-378. doi: 10.1023/A:1014893102151

Mirshekary, S., \& Lawrence, A. D. K. (2009). Academic and business ethical misconduct and cultural values: a cross national comparison. Journal of Academic Ethics, 7(3), 141-157. doi: $10.1007 / \mathrm{s} 10805-009-9093-0$

Morris, D. E., \& Kilian C. M. (2006). Do accounting students cheat? A study examining undergraduate accounting students' honesty and perceptions of dishonest behavior. Journal of Accounting, Ethics \& Public Policy, 3(5), 375-393.

Murcia, F. D-R., \& Borba, J. A. (2005). Um estudo das fraudes contábeis sob duas óticas: jornais econômicos versus periódicos acadêmicos no período de 2001-2004. Revista de Contabilidade do Mestrado em Ciências Contábeis da UERJ, 2(10), 99-114. 
Nonis, S., \& Swift, C. (2001). An examination of the relationship between academic dishonesty and workplace dishonesty: a multicampus investigation. Journal of Education for Business, 77(2), 69-77. doi: 10.1080/08832320109599052

Rakovski, C., \& Levy, E. (2007). Academic dishonesty: perceptions of business students. College Student Journal, 42(2), 466-481.

Rennie, S., \& Rudland, J. (2003). Differences in medical students' attitudes to academic misconduct and reported behaviour across years - a questionnaire study. Journal of Medical Ethics, 2(29), 97-102.

Rumyantseva, N. L. (2005). Taxonomy of corruption in higher education. Peabody Journal of Education, 80(1), 81-92.

Scanlon, P. M. (2003). Student online plagiarism: how do we respond? College Lecturing, 51(4), 161165. doi: $10.1080 / 87567550309596432$

Silva, G. A. da, Rocha, M. M. da, Otta, E., Pereira, Y. L., \& Bussad, V. S. R. (2006). Um estudo sobre a prática da cola entre universitários. Psicologia: Reflexão \& Crítica, 19(1), 18-24. doi: 10.1590/S0102-79722006000100004

Smyth, L. S., Davis, J. R., \& Kroncke, C. O. (2009). Student's perceptions of business ethics: using cheating as a surrogate for business situations. Journal of Education for Business, 84(4), 229239. doi: 10.3200/JOEB.84.4.229-239

Sutherland-Smith, W. (2010). Retribution, deterrence and reform: the dilemmas of plagiarism management in universities. Journal of Higher Education Policy and Management, 32(1), 5-16. doi: 10.1080/13600800903440519

Teixeira, A. C., \& Rocha, M. F. (2010). Cheating by economics and business undergraduate students: an exploratory international assessment. High Education, 59(6), 663-701. doi: 10.1007/s10734009-9274-1

Walker, J. (2010). Measuring plagiarism: researching what students do, not what they say they do. Studies in Higher Education, 35(1), 41-59. doi: 10.1080/03075070902912994

Wilkerson, J. (2009). Staff and student perceptions of plagiarism and cheating. International Journal of Teaching and Learning in Higher Education, 20(2), 98-105.

Witherspoon, M., Maldonado, N., \& Lacey, C. (2012). Undergraduates and academic dishonesty. International Journal of Business and Social Science, 3(1), 76-86.

Wood, J. A., Longenecker, J. G., McKinney, J. A., \& Moore, C. W. (1988). Ethical attitude of students and business professionals: a study of moral reasoning. Journal of Business Ethics, 7(4), 249257. doi: $10.1007 / \mathrm{BF} 00381828$ 